\title{
2-Methoxy-1,4-Naphthoquinone (MNQ) Inhibits Glucose Uptake and Lactate Production in Triple-Negative Breast Cancer Cells
}

\author{
Syukriyah Mat Daud, Nik Soriani Yaacob, Agustine Nengsih Fauzi*
}

\begin{abstract}
Objective: The persistent activation of aerobic glycolysis in cancer cells results in accumulation of lactate and other metabolic intermediates that contribute to tumorigenesis. Increased glycolysis is frequently dysregulated in triple-negative breast cancer (TNBC), which promotes tumor growth and immune escape. This study was conducted to investigate the effect of 2-methoxy-1, 4-naphthoquinone (MNQ), compound extracted from Impatiens balsamina on glycolytic activities in human breast adenocarcinoma, MDA-MB-231 cells. Methods: Initially, MTT proliferation assay was used to test the cell viability with various doses of MNQ (5-100 $\mu \mathrm{M})$. As the half maximal inhibitory concentration $\left(\mathrm{IC}_{50}\right)$ was obtained, glucose uptake and lactate assays of the cells were tested with $\mathrm{IC}_{50}$ dose of MNQ. The treated cells were also subjected to gene and protein analysis of glycolysis-related molecules (GLUT1 and Akt). Results: The results showed that MNQ decreased the percentage of MDA-MB-231 cell viability in a dose-dependent manner with the $\mathrm{IC}_{50}$ value of $29 \mu \mathrm{M}$. The percentage of glucose uptake into the cells and lactate production decreased significantly after treatment with MNQ as compared to untreated cells. Remarkably, the expressions of GLUT1 and Akt molecules decreased in MNQ-treated cells, suggesting that the inhibition of glycolysis by MNQ is GLUT1-dependent and possibly mediated by the Akt signaling pathway. Conclusion: Our findings indicate the ability of MNQ to inhibit the glycolytic activities as well as glycolysis-related molecules in MDA-MB-231 cells, suggesting the potential of MNQ to be further developed as an effective anticancer agent against TNBC cells.
\end{abstract}

Keywords: Glycolysis- triple-negative breast cancer- 2-Methoxy-1,4-Naphthoquinone- glucose uptake- GLUT1-Akt

Asian Pac J Cancer Prev, 22, Anticancer Activity of Natural Compounds: HOW's on Methods and Reports Suppl, 59-65

\section{Introduction}

Breast cancer commonly arises from uncontrollable growth of cells from the inner lining of milk ducts or the lobules that supply the ducts with milk (Sharma et al., 2010). Breast cancer remains as the most common life-threatening cancer and the leading cause of cancer death in women worldwide. In Asia, breast cancer is the most common cancer diagnosed in women, accounting for $22.3 \%$ of all cancer cases in women, followed by colorectal, lung, and cervical cancer. In 2018, it was estimated that about 911,014 new breast cancer cases and 310,577 cancer deaths were recorded (Bray et al., 2018). Triple negative breast cancer (TNBC), which accounts for approximately $15 \%$ to $20 \%$ of breast cancer cases, is characterized by lack expression of the three most common breast cancer receptors; estrogen receptor (ER), progesterone receptor (PR), and human epidermal growth factor receptor-2 (HER2). TNBC is associated with poorer outcome compared to other breast cancer subtypes (Sorlie, et al., 2003; Gierach et al., 2010; Mavaddat et al., 2010;
Lim et al., 2016).

The metabolic properties of cancer cells are different from those of normal cells. Most of cancer cells undergo aerobic glycolysis, characterized by the increased of glycolysis rate and lactate production (Hamanaka and Chandel, 2012). Glycolysis and mitochondrial oxidative phosphorylation (OXPHOS) are the two major metabolic pathways responsible for generating ATP, a coenzyme that is accountable for generating energy in the cellular processes. However, due to the hypoxic microenvironment of cancer cells, glycolysis becomes the preferred pathway rather than mitochondrial OXPHOS for their energy requirements. The dependence of cancer cells on glycolysis contributes to the generation of biosynthetic precursors that are required for cell proliferation (Vander Heiden et al., 2009). These precursors include amino acids, ribose sugar, and NADPH that generates nucleotides for DNA and RNA synthesis (Lunt and Vander Heiden, 2011; Fadaka et al., 2017).

The first rate-limiting step of glucose metabolism is the transport of glucose across the plasma membrane 
mediated by facilitative glucose transporters (GLUTs). GLUTs are often found overexpressed in most cancer cells and their activity in cancer cells are 10-12 folds higher than in healthy cells, indicating a strong dependence of cancer cells on GLUTs for their survival (Macheda et al., 2005). Cancer cells are also characterized by excessive lactate formation which is elevated up to 40 -fold. This condition is highly correlated with cancer aggressiveness and poor survival (Brizel et al., 2001). Besides increased glucose uptake and lactate accumulation, overexpression of glycolytic enzymes in cancer cells exhibit further difference in their metabolic properties compared to normal cells (Moreno-Sanchez et al., 2007). Thus, targeting the glycolytic pathway may be a promising way to eliminate cancer cells. The glycolytic pathway involves a series of reactions and enzymes which are all potential targets for anticancer treatment (Vander Heiden, 2011; Zhao et al., 2013). Targeting glycolysis-related molecules such as GLUTs, hexokinase II (HKII), lactate dehydrogenase A (LDHA), and glutaminase will directly limit the growth of cancer cells through inhibition of glycolysis as well as glucose uptake (Zhao et al., 2013; Granchi et al., 2014). Besides glycolysis-related molecules, their upstream regulatory molecules (such as Akt and PI3K) are also being considered as potential target molecules in cancer metabolism. Akt is a serine/threonine kinase or known as protein kinase $\mathrm{B}$ (PKB) and has a crucial role in major cellular functions including cell cycle progression, regulation of glucose metabolism, transcription and protein synthesis (Nitulescu et al., 2018). Activation of Akt stimulates glycolysis in cancer cells by increasing the expression and membrane translocation of GLUT1 (Elstrom et al., 2004).

There are various glycolytic inhibitors derived from natural compounds such as phloretin, quercetin, hesperitin, apigenin, genistin, acetogenins, and quinones (Melstrom et al., 2008; Torres et al., 2012; Granchi et al., 2014). These inhibitors can be found naturally as active compounds in plants and animals, where each of the inhibitors target different points in the glycolytic pathway (Xintaropoulou et al., 2015). Quinones for example, are plant-derived secondary metabolites that have anti-metastasis and anti-proliferation properties in cancer cells ( $\mathrm{Lu}$ et al., 2013; Kuete et al., 2016). Quinones can be divided into four types namely phenanthroquinone, anthraquinone, benzoquinone, and naphthoquinone, depending on the number of benzene rings in the structural skeleton and chemical bonds (Kumagai et al., 2012). The 2-methoxy-1, 4-napthoquinone (MNQ) can be extracted from Impatiens balsamina, an annual herb that has been used as indigenous medicine for the treatment of rheumatism and inflammation (Wang et., 2011) (Figure 1). MNQ was previously shown to be cytotoxic by suppressing the invasion and migration of several cancer cell lines including the highly metastatic TNBC cells, MDA-MB-231 (Ding et al., 2008; Wang and Lin, 2012; Liew et al., 2014). MNQ was also reported to induce apoptotic cell death by stimulating reactive oxygen species (ROS) production, which caused oxidative DNA damage and subsequent activation of JNK and $\mathrm{p} 38$ mitogen-activated protein kinase (MAPK) signaling pathway (Ong et al., 2015). In this study, we aimed to investigate the antiglycolytic potential of MNQ in MDAMB-231 cells.

\section{Materials and Methods}

\section{Cell lines and cell culture}

Human breast adenocarcinoma, MDA-MB-231 cell line was purchased from American Type Cell Culture Collection (ATCC, USA) and maintained at $37^{\circ} \mathrm{C}$ and $5 \% \mathrm{CO}_{2}$ humidified atmosphere in Dulbecco's modified Eagle's medium (DMEM) supplemented with $10 \%$ fetal bovine serum (FBS) and 1 unit/ml penicillin/streptomycin (all purchased from Thermo Scientific, USA). MNQ (C11H8O3) was purchased from Sigma-Aldrich (USA) and dissolved in dimethyl sulfoxide (DMSO) (Amresco, Canada) to make $10 \mathrm{mM}$ stock solution.

Cell proliferation assay and determination of $I C_{50}$ values

The cells were treated with various concentration of MNQ ( 5 to $100 \mu \mathrm{M}$ ) for up to $48 \mathrm{~h}$. Cell proliferation was determined using 3-[4,5-dimethylthiazole-2-yl]-2,5diphenyltetrazolium bromide (MTT) assay kit (Roche, Germany) according to the manufacturer's instructions. The absorbance of the colorimetric assay was read using microplate scanning spectrophotometer at a wavelength of $550 \mathrm{~nm}$ and a reference of $660 \mathrm{~nm}$. The inhibition concentration $\mathrm{IC}_{50}$ is defined as the concentration of MNQ that inhibits $50 \%$ cell growth.

\section{Determination of glucose uptake}

Cells were seeded in 96-well plates at a concentration of $3 \times 10^{4}$ cells/well. After $24 \mathrm{~h}$, the medium was replaced with glucose-free assay medium (Thermo Scientific, USA) supplemented with $10 \%$ FBS. The cells were treated with MNQ at the $\mathrm{IC}_{50}$ dose for 1,4 , and $8 \mathrm{~h}$ at $37^{\circ} \mathrm{C}$. The glucose uptake test was performed using Glucose Uptake Cell-Based Assay Kit (Cayman, USA) according to the manufacturer's instructions. $1 \mu \mathrm{l}$ of 2 -[N-(7-nitrobenz2-oxa-1,3-diazol-4-yl) amino]-2-deoxy-D-glucose (2-NBDG) was added to the cells for 20 minutes at $37^{\circ} \mathrm{C}$. The cells were then centrifuged and washed with $200 \mu \mathrm{l}$ of Cell-Based Assay Buffer twice. The absorbance was measured using fluorescent filter at a wavelength of 485 $\mathrm{nm}$ (excitation) and $535 \mathrm{~nm}$ (emission).

\section{Determination of lactate production}

The cells were treated with MNQ at the $\mathrm{IC}_{50}$ dose for 1,4 , and $8 \mathrm{~h}$ at $37^{\circ} \mathrm{C}$. At the end of treatment, the medium was removed, and lactate levels were measured using the L-Lactate Calorimetric Assay Kit (Abcam, UK) according to the manufacturer's instructions. The cells were harvested and deproteinized with $4 \mathrm{M}$ of perchloric acid (PCA) (Sigma-Aldrich, USA) to obtain the original concentration of the sample. Then, $50 \mu 1$ of reaction mix was added to the wells and incubated at room temperature for 30 minutes. The absorbance was read using microplate scanning spectrophotometer at a wavelength of $450 \mathrm{~nm}$ and reference of $660 \mathrm{~nm}$. 
Quantitative real-time Polymerase Chain Reaction ( $q R T$ PCR)

Total RNAs were extracted from cells using RNeasy Mini kit (Qiagen, USA) and reverse-transcribed using the RevertAid H Minus First Strand cDNA synthesis kit (Thermofisher, USA). Real-time PCR was performed in triplicates using SensiFAST SYBR ${ }^{\circledR}$ Lo-ROX kit (Bioline Reagents Ltd, UK) using primer sequences listed in Table 1. The expression of gene transcripts was normalized to the reference gene, $\beta$-actin, and relative expression values were calculated according to the $\Delta \Delta \mathrm{Ct}$ method.

\section{Western blotting}

Cell lysates were harvested by centrifugation at $12,000 \mathrm{rpm}$ for $2 \mathrm{~min}$ and lysed in lysis buffer $(50 \mathrm{mM}$ of Tris- $\mathrm{HCl}, 150 \mathrm{mM}$ of $\mathrm{NaCl}, 0.2 \% \mathrm{SDS}, 1 \mathrm{mM}$ PMSF, $2 \mu \mathrm{g} / \mathrm{ml}$ of leupeptin, $2 \mu \mathrm{g} / \mathrm{ml}$ of aprotinin and $1 \mathrm{mM}$ of $\mathrm{Na}_{3} \mathrm{VO}_{4}$ ). The protein concentrations were determined spectrophotometrically. About $50-100 \mu \mathrm{g}$ of protein samples were resolved using $10 \%$ SDS polyacrylamide gel followed by semi-dry transfer onto the PVDF membrane. The proteins were immunoblotted for GLUT1, Akt and $\beta$-actin overnight at $4{ }^{\circ} \mathrm{C}$ and subsequently reacted with horseradish peroxidase conjugated secondary antibody. Antibody-bound proteins were detected by chemiluminescence using ECL ${ }^{\text {TM }}$ Prime Western Blotting Detection reagent (GE Healthcare, UK) according to the manufacturer's protocols and visualized using the FluorChem FC2 image analyzer (DKSH, US). The band density for each treatment was normalized to the $\beta$-actin and compared to untreated group using ImageJ 1.52 software.

\section{Statistical analysis}

Data were obtained from at least three independent experiments. The values were expressed as mean \pm standard deviation. Statistical evaluation was performed using Student T-test and One-Way ANOVA with Bonferroni's Multiple Comparison test using GraphPad Prism5 and $\mathrm{P}<0.05$ was considered significant.

\section{Results}

\section{$M N Q$ inhibits $M D A-M B-231$ cell viability}

Treatment of MDA-MB-231 cells with increasing concentrations of MNQ reduced the cell viability in a dose-dependent manner (Figure 2). The cells were started to shrink and lyse as treated with higher concentration of MNQ. Eventually, the cells observed to detach from the surface indicated the cells were dead. The $\mathrm{IC}_{50}$ value

Table 1. List of Primers Used in Quantitative Real-Time PCR

\begin{tabular}{ll}
\hline Genes & Primer sequence \\
\hline b-actin & $\left(5^{\prime}\right.$ '-TGA GCG CGG CTA CAG CTT-3') Forward \\
& $\left(5^{\prime}\right.$-TCC TTA ATG TCA CGC ACG ATT T-3') Reverse \\
GLUT1 & $\left(5^{\prime}\right.$-AAC TCT TCA GCC AGG GTC CAC-3') Forward \\
& $\left(5^{\prime}\right.$-CAC AGT GAA GAT GAT GAA GAC-3') Reverse \\
Akt & $\left(5^{\prime}\right.$-TCT ATG GCG CTG AGA TTG TG-3') Forward \\
& $\left(5^{\prime}\right.$-CTT AAT GTG CCC GTC CTT GT-3') Reverse \\
\hline
\end{tabular}

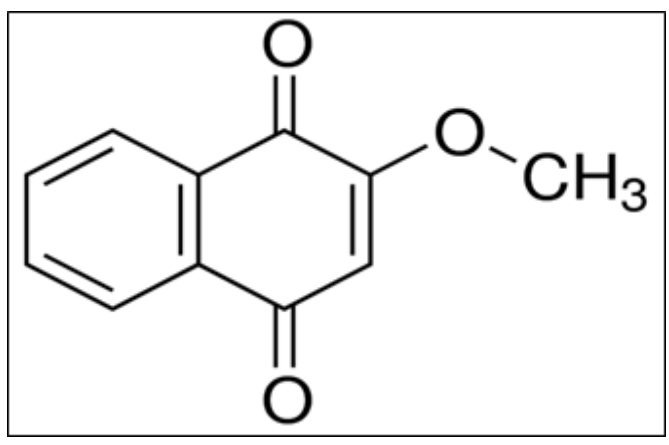

Figure 1. 2-Methoxy-1,4-Naphthoquinone (MNQ)

of MNQ observed was $29 \mu \mathrm{M}$ and this concentration of MNQ was used for the subsequent assays.

\section{Reduction of glucose uptake by $M N Q$}

Glucose uptake assay was performed in MDA-MB-231 cells treated with $\mathrm{IC}_{50}$ dose of MNQ for 1,4 , and $8 \mathrm{~h}$. Glucose uptake was represented by the

\section{A}
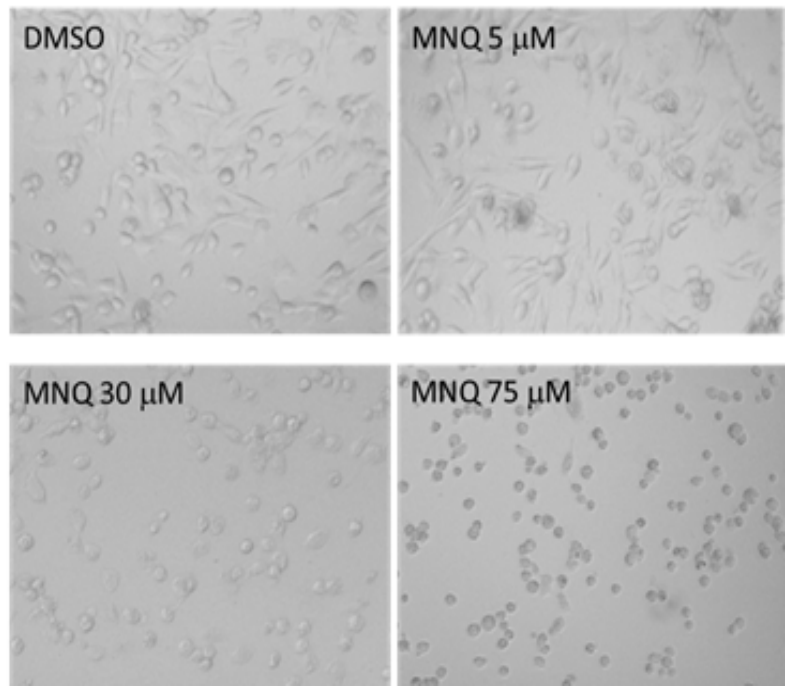

B

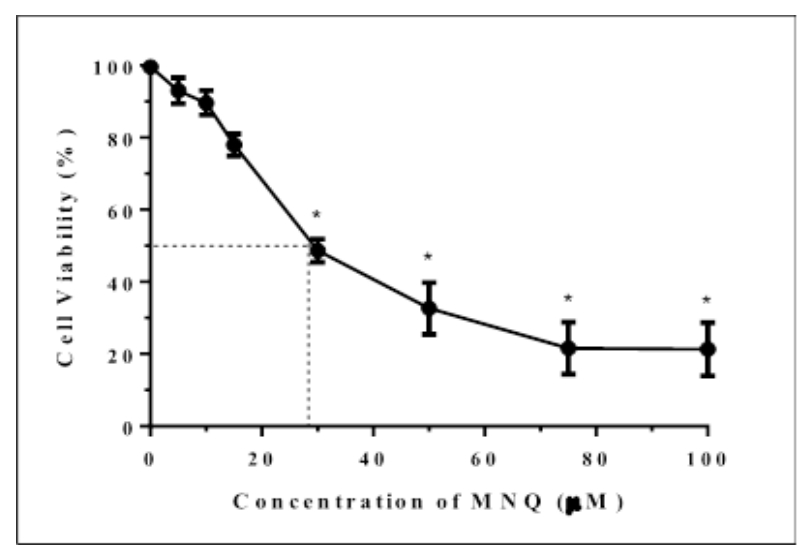

Figure 2. Dose- Dependent Effects of MNQ on the Growth of MDA-MB-231 Cells. The cells were treated with $5-100 \mu \mathrm{M}$ concentration of MNQ for $48 \mathrm{~h}$. (A) Morphology of MDA-MB-231 cells treated with MNQ (40x magnification) and (B) the viability of MDAMB-231 cells reduced significantly after treatment with increasing concentrations of MNQ. Data are expressed as mean \pm standard deviation from three independent experiments. 


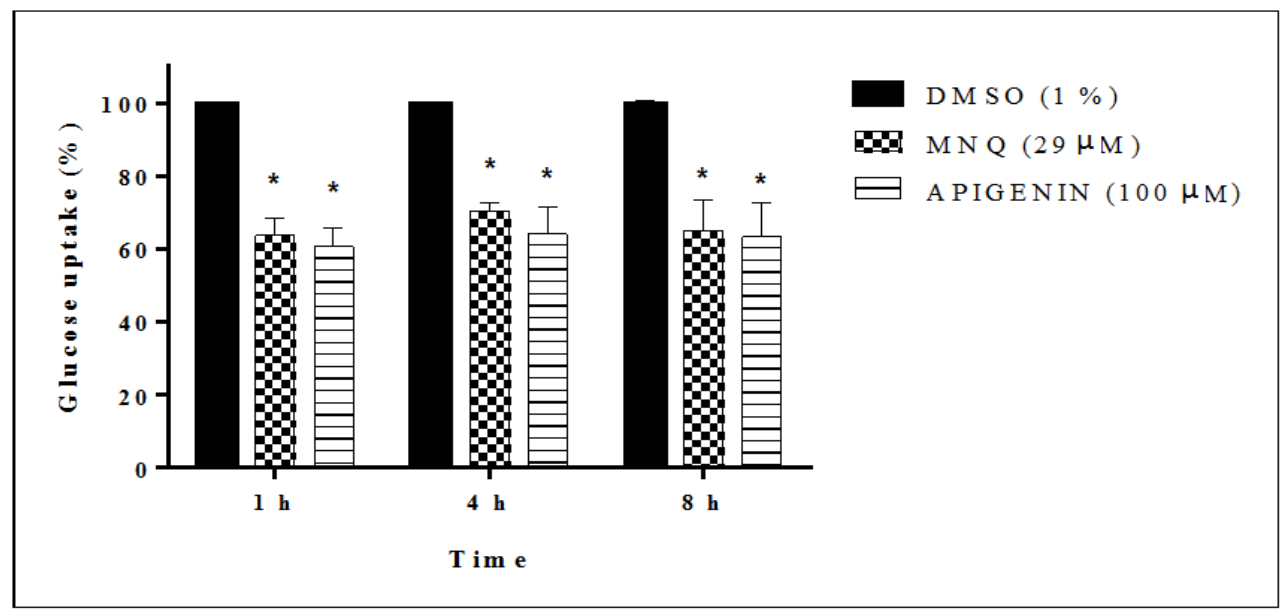

Figure 3. Percentages of Glucose Uptake by MDA-MB-231 Cells Treated with MNQ. Cells were treated with either MNQ $\left(\mathrm{IC}_{50}\right)$, DMSO $(0.5 \%)$, or apigenin $(100 \mu \mathrm{M})$ for up to $8 \mathrm{~h}$. Glucose uptake was measured based on 2-NBDG uptake into the cells and the absorbance reading was taken at 485/535 (excitation/emission) nm wavelength. Data are expressed as mean \pm standard deviation from three independent experiments. ${ }^{*} \mathrm{P}<0.05$ significantly different from the DMSO control group.

amount of fluorescence-labeled 2-NDBG probe taken up by the cells. Results show that MDA-MB-231 cell uptake of glucose decreased significantly comparable to the effect of the GLUT1 inhibitor, apigenin (Figure 3). The percentages of glucose uptake after treatment with MNQ were $76.25 \%, 87.25 \%$, and $81.75 \%$ after 1,4 , and $8 \mathrm{~h}$, respectively. Results suggest that GLUT activities, the first rate-limiting step in glycolysis, were inhibited by MNQ.

$M N Q$ inhibits lactate production in MDA-MB-231 cells

The amount of lactate produced by the cells was measured after treatment with MNQ for 1,4 , or $8 \mathrm{~h}$. Oxidation of pyruvate to lactate by LDH generates a nicotinamide-adenine dinucleotide $(\mathrm{NAD}+)$ that interacts with a probe (in the reaction mixture) to produce a dark blue color. Decreased intensity of the dark blue color indicates the reduction of lactate production. The amount of lactate production was significantly reduced with values of 14.83 and $14.43 \mathrm{nmol} / \mu \mathrm{l}$ at 4 and $8 \mathrm{~h}$, respectively, following MNQ treatment compared to the DMSO control (Figure 4).

$M N Q$ down-regulates the expression of GLUT1 and Akt at gene and protein levels

To gain insights into the antiglycolytic mechanism of MNQ, we determined the expression of glycolysis-related molecules, GLUT1 and Akt after 1, 4, 8 and $24 \mathrm{~h}$ post-treatment. The mRNA expression of these proteins was analyzed by qRT-PCR, and the results indicated that MNQ downregulated the mRNA expression of GLUT1 and Akt, in a time-dependent manner (Figure 5A\&B). The expression of GLUT1 and Akt genes were further analyzed at protein synthesis level. We found that MNQ slightly decreased the expression of GLUT1 and Akt protein in MDA-MB-231 cells (Figure 5C). The reduction of the expression of both GLUT1 and Akt molecules by MNQ is positively correlated with the inhibition of glucose uptake in MDA-MB-231 cells.

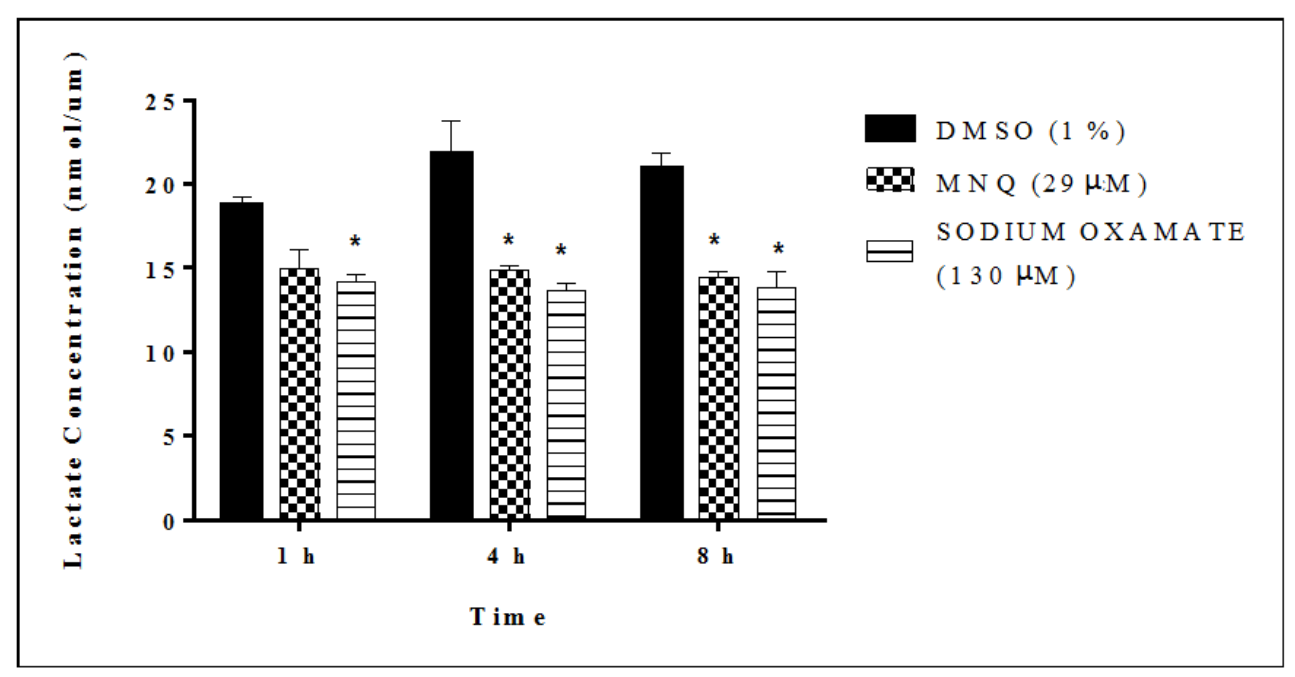

Figure 4. Lactate Concentration of MDA-MB-231 Cells after Treatment with MNQ. Cells were treated with either MNQ $\left(\mathrm{IC}_{50}\right)$, DMSO $(0.5 \%)$ or sodium oxamate $(100 \mu \mathrm{M})$ for up to $8 \mathrm{~h}$. Lactate concentration was calculated based on the standard curve and absorbance reading was measured at a wavelength of $450 \mathrm{~nm}$. Data are expressed as mean \pm standard deviation from three independent experiments. ${ }^{*} \mathrm{P}<0.05$ significantly from the DMSO control group. 

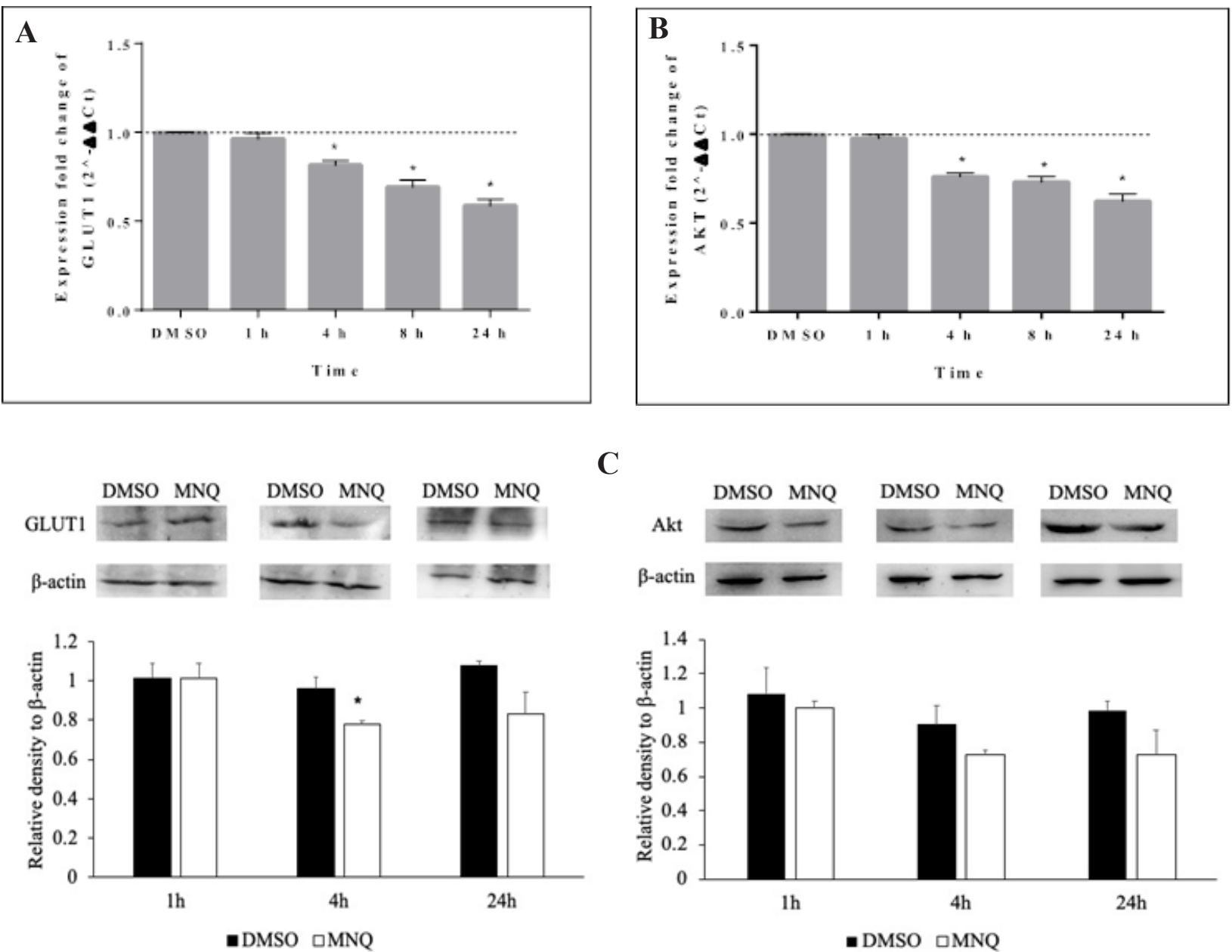

C

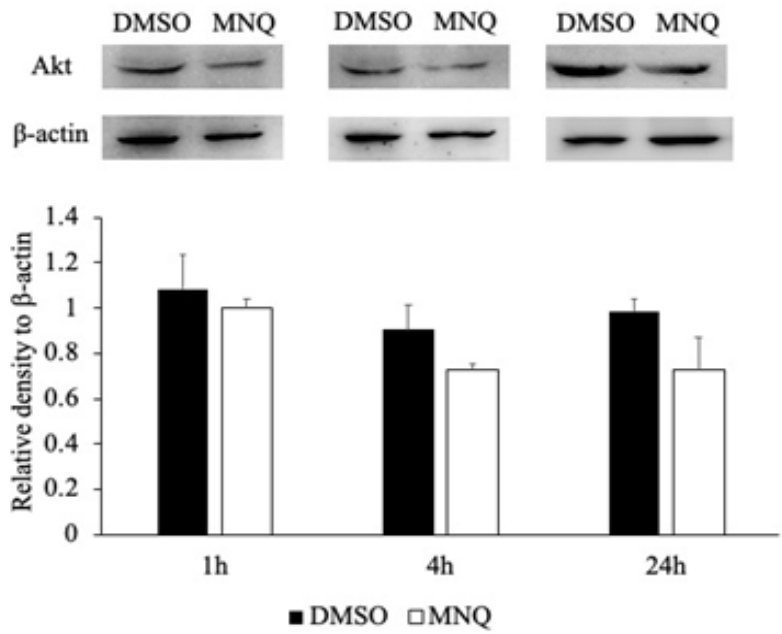

Figure 5. The Expression of GLUT1 and Akt in MDA-MB-231 Cells (A) MNQ downregulated the expression of GLUT1 and (B) Akt genes, following 1,4 and $24 \mathrm{~h}$ post-treatment. (C) MNQ caused some reduction in the expression of GLUT1 and Akt protein following 1,4 and $24 \mathrm{~h}$ post-treatment. Data are expressed as mean \pm standard deviation from three independent experiments. $* \mathrm{P}<0.05$ significantly from the DMSO control group.

\section{Discssion}

High rate of glycolysis and glucose uptake in cancer cells contributes to tumorigenesis through production of glycolytic intermediates necessary for proliferating cells (Lunt and Vander Haiden, 2011). Rapid proliferation of cancer cells exhausts the nutrient and oxygen supplies, thus resulting in a hypoxic microenvironment that drives the development of pre-malignant lesions. Increased glycolysis and excessive lactate production further result in an acidic condition, which causes a significant decrease in local extracellular $\mathrm{pH}$ and the development of microenvironmental acidosis. Through acidification, tumorigenesis is augmented and the cells acquire resistance against therapeutic strategies and chemical drugs (DeClerck and Elble, 2010; Wu et al., 2012).

Increased aerobic glycolysis is associated with metastasis activity in cancer cells (Gatenby and Gillies, 2004). Human breast adenocarcinoma cell line, MDA-MB-231, is characterized by highly aggressive and metastatic phenotype due to the lack of expression of ER, PR, and HER2 (Holliday and Speirs, 2011). MDA-MB-231 cells display higher aerobic glucose consumption rates compared to non-invasive MCF-7 breast cancer cell lines (Kunkel et al., 2003). MDA-MB-231 cells are also reported to exhibit GLUT1 overexpression that facilitates the transport of glucose across the plasma membrane (Laudanski et al., 2003) and increased glucose metabolism and GLUT1 expression have been correlated with cancer aggressiveness and poor prognosis (Kunkel et al., 2003).

In line with previous reports (Ding et al., 2008; Wang and Lin, 2012; Liew et al., 2014; Ong et al., 2015), we showed that MNQ, a compound extracted from Impatiens Balsamina, inhibited the growth and proliferation of MDA-MB-231 cells in a dose-dependent manner, with visible morphological changes. Importantly, we demonstrated for the first time that MNQ inhibited glycolytic activities in MDA-MB-231 cells via inhibition of glucose uptake and downregulation of GLUT1 expression. The rate of glucose uptake decreased significantly in MNQ-treated cells, comparable to the effect of apigenin, a polyphenol that acts as an inhibitor of GLUTs in several cancer cells, possibly by inhibiting protein-tyrosine kinase (Melstrom et al., 2008; Xu et al., 2014).

Besides determining glucose uptake activity, evaluation of lactate production is an important method to assess the glycolytic activities in cancer cells. Lactate is produced by conversion of pyruvate (the end product of

Asian Pacific Journal of Cancer Prevention, Vol 22 
glycolysis) by lactate dehydrogenase (LDH). Our results showed that MNQ decreased the amount of lactate, to a level comparable to the effect of sodium oxamate that acts as a competitive inhibitor of LDH and is a structural analogue of pyruvate. Cancer cells convert about $66 \%$ of pyruvate to lactate, even in aerobic condition (Warburg et al., 1927). Thus, inhibition of glucose uptake into the cells via GLUTs will automatically reduce lactate production. Although lactate is considered as a side or waste product in normal cell metabolism, studies proved that the presence of lactate in cancer cells is important for angiogenesis, cell migration, and metastasis (Le et al., 2010; San-Millan and Brooks, 2017). Overproduction of lactate is also associated with the activation of transforming growth factor (TGF)-beta 2, a key pathophysiological factor in malignant cells such as glioblastoma, that could lead to immune suppression as well as increased tumor growth, invasion, and metastasis (Seliger et al., 2013). Reduction of lactate can disrupt cancer cell metabolism and eventually inhibit growth and proliferation of cancer cells (Sheng et al., 2012; Miao et al., 2013). Several metabolic inhibitors from natural compounds are being explored including thiazolidinediones, naphthoquinones and their derivatives for the potential to inhibit the M2 isoform of pyruvate kinase (PKM2) that is highly expressed in cancer cells, resulting in reduced lactate production (Cerella et al., 2013). Our data showed reduced production of lactate in MNQ-treated cells that positively correlated with the inhibition of glucose uptake. The reduction may potentially be associated with alteration of several glycolytic enzymes such as LDHA, PKM2, and HKII but this have yet to be determined.

Reduced GLUT expression in cancer cells was often related to the suppression of cancer cell growth and proliferation ( Kueck et al., 2007; Chan et al., 2011; Liu et al., 2012). Down-regulation of GLUT1 mRNA and protein expression by MNQ further supports the anti-glycolytic action of this natural compound. The downregulation of GLUT1 by MNQ may be caused by; i) direct binding of MNQ to the GLUT1 outward-facing glucose-binding site, thus blocking the glucose transportation (Deng et al., 2014) or ii) by inhibiting the GLUT1 upstream signaling pathways, thus preventing the activation of GLUT1. The expression of GLUT1 is influenced by the upstream regulatory gene, Akt, (Basu et al., 2015; Siska et al., 2016) which was also found to be significantly downregulated in this study. Activation of PI3K/Akt/mTOR signaling pathway leads to the translocation of GLUT1 to the plasma membrane for glucose uptake. Hence, targeting the PI3K/ Akt/mTOR signaling pathway is an alternative strategy to suppress cancer proliferation through inhibition of glycolysis (Elstrom et al., 2004; Kueck et al., 2007; Brown and Banerji, 2017).

Besides targeting PI3K/Akt/mTOR signaling pathway, MNQ may possibly inhibit the GLUT1 activity through the serine/threonine protein kinase $\mathrm{C}$ (PKC), which is an upstream regulator of GLUT1. PKC can rapidly initiate glucose uptake via phosphorylation of GLUT1 through S266 modification within the GLUT1 structure (Witters et al., 1985; Siska and Rathmell, 2015). A study by Yew et al. (2015) showed that MNQ suppressed the PKC $\beta I$, $\delta, \zeta$ expression in human Burkitt's lymphoma cell line (Raji cells), hence could be considered as a potent PKC inhibitor. Further experiments are needed to investigate the effects of MNQ on the regulation of PKC expression in MDA-MB-231 cells.

In conclusion, the mechanism of antiglycolytic action of MNQ involves interference with glucose transport and metabolism, possibly through the Akt signaling pathway. This study demonstrated for the first time the potential use of MNQ compound as an antiglycolytic agent against TNBC cells. Nevertheless, more preclinical studies are needed to prove its effectiveness.

\section{Acknowledgements}

\section{Funding statement}

This research was funded by the Universiti Sains Malaysia (USM) Short Term grant (304.PPSP.61313154). SM Daud was supported by USM Fellowship Scheme and Mybrain 15 from the Ministry of Higher Education Malaysia.

\section{References}

Basu S, Hubbard B, Shevach EM (2015). FOXP3-mediated inhibition of Akt inhibits GLUT1 (glucose transporter 1) expression in human T regulatory cells. J Leukoc Biol, 97, 279-83.

Bray F, Ferlay J, Soerjomataram I, et al (2018). Global Cancer Statistics 2018: Globocan estimates of incidence and mortality worldwide for 36 cancers in 185 countries. $C A$ Cancer J Clin, 68, 394-424.

Brizel DM, Schroeder T, Scher RL, et al (2001). Elevated tumor lactate concentrations predict for an increased risk of metastases in head-and-neck cancer. Int J Radiat Oncol Biol Phys, 51, 349-53.

Brown JS, Banerji U (2017). Maximising the potential of Akt inhibitors as anti-cancer treatments. Pharmacol Ther, 172, 101-15.

Chan DA, Sutphin PD, Nguyen P, et al (2011). Targeting GLUT1 and the warburg effect in renal cell carcinoma by chemical synthetic lethality. Sci Transl Med, 3, 94-170.

Cerella C, Radogna F, Dicato M, et al (2013). Natural compounds as regulators of the cancer cell metabolism. Int J Cell Biol, 2013, Article Id 639401, 16 Pages.

Declerck K, Elble RC (2010). The role of hypoxia and acidosis in promoting metastasis and resistance to chemotherapy. Front Biosci, 15, 213-25.

Deng D, Xu C, Sun P, et al (2014). Crystal structure of the human glucose transporter GLUT1. Nature, 510, 121-30.

Ding ZS, Jiang FS, Chen NP, et al (2008). Isolation and identification of an anti-tumor component from leaves Impatiens balsamina. Molecules, 13, 220-9.

Elstrom RL, Bauer DE, Buzzai M, et al (2004). Akt stimulates aerobic glycolysis in cancer cells. Cancer Res, 64, 3892-9.

Fadaka A, Ajiboye B, Ojo O, et al (2017). Biology of glucose metabolization in cancer cells. J Oncol Sci, 3, 45-51.

Gatenby RA, Gillies RJ (2004). Why do cancers have high aerobic glycolysis?. Nat Rev Cancer, 4, 891-9.

Granchi C, Fancelli D, Minutolo F (2014). An update on therapeutic opportunities offered by cancer glycolytic metabolism. Bioorg Med Chem Lett, 24, 4915-25.

Gierach GL, Burke A, Anderson WF (2010). Epidemiology of triple negative breast cancers. Breast Dis, 32, 5-24.

Hamanaka RB, Chandel NS (2012). Targeting glucose 
metabolism for cancer therapy. $J$ Exp Med, 209, 211-5.

Holliday DL, Speirs V (2011). Choosing the right cell line for breast cancer research. Breast Cancer Res, 13, 215.

Kueck A, Opipari AW, Griffith KA, et al (2007). Resveratrol inhibits glucose metabolism in human ovarian cancer cells. Gynecol Oncol, 107, 450-7.

Kuete V, Omosa LK, Tala VR, et al (2016). Cytotoxicity of plumbagin, rapanone and 12 other naturally occurring quinones from Kenyan flora towards human carcinoma cells. BMC Pharmacol Toxicol, 21, 60.

Kumagai Y, Shinkai Y, Miura T, Cho AK (2012). The chemical biology of naphthoquinones and its environmental implications. Annu Rev Pharmacol Toxicol, 52, 221-47.

Kunkel M, Reichert TE, Benz P, et al (2003). Overexpression of GLUT1 and increased glucose metabolism in tumors are associated with a poor prognosis in patients with oral squamous cell carcinoma. Cancer, 97, 1015-24.

Laudanski P, Swiatecka J, Kovalchuk O, Wolczynski S (2003). expression of GLUT1 gene in breast cancer cell lines MCF-7 and MDA-MB-231. Ginekol Pol, 74, 782-5.

Le A, Cooper CR, Gouw AM, et al (2010). Inhibition of lactate dehydrogenase a induces oxidative stress and inhibits tumor progression. Proc Natl Acad Sci U S A, 107, 2037-42.

Liew K, Yong PVC, Lim YM, et al (2014). 2-methoxy-1,4naphthoquinone (MNQ) suppresses the invasion and migration of a human metastatic breast cancer cell line (MDA-MB-231). Toxicol In Vitro, 28, 335-9.

Lim, SO, Li CW, Xia W, et al (2016). EGFR signaling enhances aerobic glycolysis in triple-negative breast cancer cells to promote tumor growth and immune escape. Cancer Res, 1, 1284-96.

Liu Y, Cao Y, Zhang W, et al (2012). A small-molecule inhibitor of glucose transporter 1 downregulates glycolysis, induces cell-cycle arrest, and inhibits cancer cell growth in vitro and in vivo. Mol Cancer Ther, 11, 1672-82.

Lu JJ, Bao JL, Wu GS, et al (2013). Quinones derived from plant secondary metabolites as anti-cancer agents. Anticancer Agents Med Chem, 13, 456-63.

Lunt SY, Vander Heiden MG (2011). Aerobic glycolysis: meeting the metabolic requirements of cell proliferation. Annu Rev Cell Dev Biol, 27, 441-64.

Macheda ML, Rogers S, Best JD (2005). Molecular and cellular regulation of glucose transporter (GLUT) proteins in cancer. J Cell Physiol, 202, 654-62.

Mavaddat N, Rebbeck TR, Lakhani SR, et al (2010). Incorporating tumour pathology information into breast cancer risk prediction algorithms. Breast Cancer Res, 12, R28

Melstrom LG, Salabat MR, Ding XZ, et al (2008). Apigenin inhibits the GLUT1 glucose transporter and the phosphoinositide 3-kinase/Akt pathway in human pancreatic cancer cells. Pancreas, 37, 426-31.

Miao P, Sheng S, Sun X, et al (2013). Lactate dehydrogenase a in cancer: a promising target for diagnosis and therapy. IUBMB Life, 65, 904-10.

Moreno-Sanchez R, Rodriguez-Enriquez S, Marin-Hernandez A, Saavedra E (2007). Energy metabolism in tumor cells. FEBS J, 274, 1393-418.

Nitulescu GM, Van De Venter M, Nitulescu G, et al (2018). The Akt pathway in oncology therapy and beyond (Review). Int J Oncol, 53, 2319-31.

Ong JYH, Yong PVC, Lim YM, Ho ASH (2015). 2-methoxy-1,4-naphthoquinone (MNQ) induces apoptosis of a549 lung adenocarcinoma cells via oxidation-triggered JNK and p38 MAPK signaling pathways. Life Sci, 135, 158-64.

San-Millan I, Brooks GA (2017). Reexamining cancer metabolism: lactate production for carcinogenesis could be the purpose and explanation of the Warburg effect. Carcinogenesis, 38, 119-33.

Seliger C, Leukel P, Moeckel S, et al (2013). Lactate-modulated induction of THBS-1 activates transforming growth factor (TGF)-beta 2 and migration of glioma cells in vitro. PLOS One, 8, 78935-42.

Sharma GN, Dave R, Sanadya J, et al (2010). Various types and management of breast cancer: An Overview. J Adv Pharm Technol Res, 1, 109-26.

Sheng SL, Liu JJ, Dai YH, et al (2012). Knockdown of lactate dehydrogenase a suppresses tumor growth and metastasis of human hepatocellular carcinoma. FEBS J, 279, 3898-910.

Sorlie T, Tibshirani R, Parker J, et al (2003). Repeated observation of breast tumor subtypes in independent gene expression data sets. Proc Nat Acad Sci U S A, 100, 8418-23.

Siska PJ, Rathmell JC (2015). PKCs sweeten cell metabolism by phosphorylation of GLUT1. Mol Cell, 58, 711-12.

Siska PJ, Van Der Windt GJW, Kishton RJ, et al (2016). Suppression of GLUT1 and glucose metabolism by decreased Akt/MTORC1 signaling drives T cell impairment in B cell leukemia. J Immunol, 197, 2532-40.

Torres MP, Rachagani S, Purohit V, et al (2012). Graviola: A novel promising natural-derived drug that inhibits tumorigenicity and metastasis of pancreatic cancer cells in vitro and in vivo through altering cell metabolism. Cancer Lett, 323, 29-40.

Vander Heiden MG, Cantley LC, Thompson CB (2009). Understanding the Warburg effect: the metabolic requirements of cell proliferation. Science, 324, 1029-33.

Vander Heiden MG (2011). Targeting cancer metabolism: a therapeutic window opens. Nat Rev Drug Discov, 10, 671-84.

Wang YC, Li WY, Wu DC, et al (2011). In vitro activity of 2-methoxy-1,4-naphthoquinone and stigmasta-7,22diene-3 $\beta$-ol from Impatiens balsamina $L$. against multiple antibiotic-resistant Helicobacter pylori. eCAM, 2011, Article Id 704721, 8 Pages.

Wang YC, Lin YH (2012). Anti-gastric adenocarcinoma activity of 2-methoxy-1,4-naphthoquinone, an anti-Helicobacter pylori compound from Impatiens balsamina L. Fitoterapia, 83, 1336-44.

Warburg O, Wind F, Erwin N (1927). The metabolism of tumor in the body. J Gen Physiol, 8, 519-30.

Witters LA, Vater CA, Lienhard GE (1985). Phosphorylation of the glucose transporter in vitro and in vivo by protein kinase C. Nature, 315, 777-78.

Wu H, Ding Z, Hu D, et al (2012). Central role of lactic acidosis in cancer cell resistance to glucose deprivation-induced cell death. J Pathol, 227, 189-99.

Xintaropoulou C, Ward C, Wise A, et al (2015). A comparative analysis of inhibitors of the glycolysis pathway in breast and ovarian cancer cell line models. Oncotarget, 6, 256-67.

$\mathrm{Xu}$ YY, Wu TT, Zhou SH, et al (2014). Apigenin supressess GLUT1 and p-Akt expression to enhance the chemosensitivity to cisplatin of laryngeal carcinoma Hep-2 cells: an in vitro study. Int J Clinl Exp Pathol, 7, 3938-47.

Yew W, Kitson L, Hock A, Chiew G, Mooi L (2015). 2-methoxy1,4-naphthoquinone (MNQ) suppresses protein kinase $\mathrm{C}$ Beta I, Delta, and C expression in Raji cells. J Appl Pharm Sci, 5, 001-5.

Zhao Y, Butler EB, Tan M (2013). Targeting cellular metabolism to improve cancer therapeutics. Cell Death Dis, 4, 532-42.

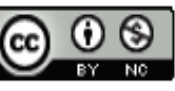

This work is licensed under a Creative Commons AttributionNon Commercial 4.0 International License.

Asian Pacific Journal of Cancer Prevention, Vol 22 